Max-Planck-Institut für demografische Forschung

Max Planck Institute for Demographic Research

Konrad-Zuse-Strasse 1 - D-18057 Rostock · GERMANY

Tel +49 (0) 3812081 - 0; Fax +49 (0) 3812081 - 202;

http://www.demogr.mpg.de

MPIDR WORKING PAPER WP 2006-050

DECEMBER 2006 (REVISED APRIL 2008)

\title{
On the psychological determinants of fertility.
}

\section{A panorama of concepts and approaches, and evidence from eastern Germany}

Holger von der Lippe (vdlippe@demogr.mpg.de)

This working paper has been approved for release by: Laura Bernardi (bernardi@demogr.mpg.de) Head of the Independent Research Group on The Culture of Reproduction.

(C) Copyright is held by the authors.

Working papers of the Max Planck Institute for Demographic Research receive only limited review. Views or opinions expressed in working papers are attributable to the authors and do not necessarily reflect those of the Institute. 


\title{
On the psychological determinants of fertility.
}

\section{A panorama of concepts and approaches, and evidence from eastern Germany}

\author{
Holger von der Lippe
}

\begin{abstract}
In this paper we study the transition to parenthood, analyzing data from three waves of a psychological longitudinal survey from Rostock, eastern Germany. We apply hazard regressions in order to predict the timing of first births of 117 men and 124 women born in 1970 and 1971. Subjects, who were in their 20s during the 1990s, made their family decisions during the most turbulent times of societal transformation in eastern Germany following unification. We hypothesized a crucial relevance of personality traits, copingstyles, and other psychological variables for the prediction of fertility in this context. Results for men show that dispositional self-actualization and internal control-styles as well as a tendency to social withdrawal decrease the probability of fatherhood. For women, dispositional emotional stability and mental health decrease the probability of motherhood, whereas a tendency toward rationalization increases it. We discuss findings in light of the gender-specific life-span development of people's personality and control behavior.
\end{abstract}




\section{Introduction}

Demography always has had an interest in psychological theories of decision-making when aiming at explain the causes and mechanisms of people's childbearing behavior. Instances of questions that demographers dealing with fertility and family dynamics would wish to address to psychologists are: Which are the underlying personal motives that explain why people want to start a family and have (a certain number of) children? Is the individual desire for children created early in people's lives (and thus an exogenous factor in demographic analyses) or is it affected by later stages of the unfolding of the individual life course (and thus an endogenous factor in itself)? Concerning the behavioral mechanisms involved, questions read for instance: Which process activates people's desire for children to become action-guiding? In what ways do couples negotiate the number and the timing of children? What makes people postpone or bury their childbearing intentions or, conversely, what turns formerly childindifferent self-fulfillers into family-desirers around the age of 30 ?

It is evident that psychology has something to contribute to these questions, or rather: should have something to contribute. ${ }^{1}$ The potential mutual stimulation of the disciplines has frequently been begun, forgotten, taken up, then again forgotten, and so on. Today, the diagnosis holds that there is some body of literature on the psychology of population (beginning with Fawcett's volume of the same name, 1973), yet it is also true that this literature is a produce of rather heterogeneous, infrequent and little systematic or poorly interrelated research projects. Therefore, one goal of this article is to identify one of the possible red threads through the knowledge available on the psychology of fertility and family dynamics. This paper also presents recent evidence on the psychological determinants of first birth in eastern Germany of the 1990s.

\footnotetext{
${ }^{1}$ Some psychological studies are involved in research on the determinants of demographic behavior such as mortality (Maier et al., 2003, Maier \& Smith, 1999), public health, and migration (Ainsaar, 2004); for the scope of this article we will exclusively refer to fertility research.
} 


\section{Psychological covariates and fertility behavior: Examples of a rare interdisciplinary connection}

All scientific approaches to human fertility entail, more or less explicitly, a theory of social action. Such theory, in brief, consists of a set of conjectures in general terms answering the questions of why, under which conditions, and in which way people act in the way they do. In the field of demography, theories of action are usually dominated by economic or sociological approaches, but rarely by psychological ones. From our perspective, this has one major reason. Whilst demography as a prototypical "interdiscipline" (Caldwell) is usually very open to contributions from all disciplines, academic psychology has stayed strangely reserved to the question of the determinants of demographically relevant behavior, such as life-course decision making. The reserve is striking, yet difficult to explain. By consequence, psychological scholars often have to break new grounds when starting to work in this field-instead of harvesting from fertile lands. At this point in time, there have been some contributions to the field of fertility by psychologists, but they have either not been followed-up by any other researcher or they were made by scientists or approaches marginal to either field. The next paragraphs provide instances of such contributions.

When being primed with the keyword "psychological contribution to fertility research", we usually think first of the Value of Children (VOC) approach. Indeed, the approach, which originated in the 1970s (Hoffman \& Hoffman, 1973), has been influential throughout the recent decades (Michaels \& Goldberg, 1988, Friedman et al., 1994, Nauck, 2001, Nickel \& Quaiser-Pohl, 2001). Its primary target it to document motivations for having children, to organize them in meaningful conceptual schemes, and to study their interaction with other variables. Herein, value is seen as a concept situated between sociology and psychology. Values are "anchored in psychological needs, tied to the social structure and subject to cultural variation" (Hoffman \& Hoffman, 1973). Whilst the VOC research program has produced a large amount of empirical and intercultural comparative literature, it has been pursued (and quoted) chiefly by sociologists. From a psychological point of view, however, it remains unsatisfactory lacking an explanation how values that a group of people may share 
relate to interpersonal individual differences such as attitudes, intentions, life goals, or personality. By consequence, the VOC approach attains its highest explanatory capacity for differences between the fertility rates of different countries (Nickel \& Quaiser-Pohl, 2001), but does not fully address the question of inter-individual variation.

In the German literature of the late 1970s and early 1980s, a number of studies aimed at resuming the question on the psychological determinants and mechanisms of fertility behavior (von Rosenstiel et al., 1986, Nerdinger et al., 1984, Stengel et al., 1983). The gist of their approaches was to uncover subgroups within a given population that indicate distinct "generative structures" (Mackenroth, 1953, quoted from von Rosenstiel et al., 1986) and to trace these subgroups back to differential psychological traits. Some of these studies have led to instructive results. A short-term longitudinal study of West German couples by von Rosenstiel et al. (ibid.), for instance, has shown that psychological variables of attitudes and perceptions explain to a degree of $\mathrm{R}^{2}=.47$ whether or not childless couples will have a child within a one-year interval. The explanatory variables consist in ratings of people's extrinsic values (leisure time orientation, the perceived instrumentality of children for personal wealth and for emotional support at old age) and the perceived approval of having a child by relevant others. The study also has pointed out that given good psychological measures, other factors such as employment, living arrangements as well as childbearing desires and child-timing intentions did not contribute additionally to the fit of the statistical model of childbearing behavior (von Rosenstiel et al., 1986: 157ff.). Symptomatically, however, these studies have received little attention from the psychological as well as from the demographic field.

A more recent and carefully designed resumption of the question of the psychological determinants of fertility behavior is presented by the theoretical and empirical work by Warren Miller (1992, 1994, 1995). The author takes a different approach, presenting the important psychological distinctions between motivations, desires, and intentions as potential antecedents of people's behavior. He claims that there is a decisive, yet often overlooked, difference between various targets of these motivations, desires, and 
intentions. ${ }^{2}$ For an individual, these constructs may be directed either (i) at just having a(nother) child, (ii) at having a certain number of children, or (iii) at the timing of a(nother) child-or at all of this at the same time. Miller \& Pasta (1994) find that adequately operationalized measures of intentions are strong predictors of proceptive behavior (i.e., trying to get pregnant) in a model with some other measures such as perceived fecundity or parents favoring having a grand-child. Depending on the model specification of "proceptive behavior", , child-timing intentions are "by far the strongest predictors for the parity-zero couples and are equal for husbands and wives. They are much less strong for the parity-one couples" (Miller \& Pasta, 1994: 547). Childbearingintentions and child-number intentions are also relevant in most of the models, whereas life-cycle variables such as age, age at marriage, marital duration, or age of first child do not remain in the model (except "being divorced"). The prediction power of the models ranges from $\mathrm{R}^{2}=.44$ to .59 depending on the model specifications. Miller's approach, which has its strengths in the refinement and differentiation of intention-measures, provides a convincing answer to the long-standing bellyaches of demographers concerning the weak predictive power of "desire-for-children" survey items (ref. Noack \& Ostby, 2002).

However, it is obvious that the more precisely and action-oriented we measure these intentions, the more they themselves assume the quality of an explanandum and require an original psychological explanation. The same holds for child-number desires and childbearing motivations both of which are the most proximate determinants of intentions (cf. Miller 1994, Miller \& Pasta 1994). ${ }^{4}$ Without going into greater detail, it is important to note that Miller (1992) presents empirical evidence of the relevance of

\footnotetext{
2 In this triad "intention" is the most concrete and action-related psychological construct, whereas "motivation" is least so.

${ }^{3}$ Proceptive behavior is captured by an ordinal scale from 1 to 8 according to the onset of this behavior within the intervals of the longitudinal study.

4 This question, however, opens up wide scientific debate, ranging from psychoanalytical to sociohistorical explanations of human reproductive desires. This is clearly beyond the scope of this literature review, which sets its limits to the empirical psychological determinants of childbearing behavior.
} 
personality traits (nurturance and affiliation) and of specific early-life experiences (experiences with the own mother) in explaining these intentions, desires, and motivations. Miller finds that "childbearing motivation is built upon and merges from a substrate of individual traits that govern the human tendency to form attachments and perform care-taking" (ibid.: 280). His results suggest that, in particular, the trait of "nurturance" (giving sympathy and comfort; assisting others whenever possible) and of "affiliation" (enjoying being with friends and people in general; maintaining associations with people) are positively related to childbearing motivation. The former is equally strong for men and women, the latter is somewhat stronger for men than it is for women. By contrast, the trait of "autonomy" (trying to break away from constraints; enjoying being unattached and free) has a negative impact on childbearing motivation, whilst there is a zero-correlation (no sex-differences for these traits) for "achievement" (aspiring to accomplish difficult tasks; responding positively to competition). ${ }^{5}$

Results from a German panel study titled "The Options of Life Planning by Young Couples" by Schneewind and Vaskovics (BMFSFJ, 1996), point into a similar direction. In an analysis of the psychological antecedents and concomitants of childbearing behavior by childless couples, Schneewind (2000: 343f.) finds that "a great deal of the perceived motivational potential pro or con parenthood resides in the personality and relationship realm, suggesting that more attention should be directed to these particular aspects". Although the study lacks the use of standardized personality inventories, it reveals that psychological differences, such as in the self-concept, in mood, life-styles, and relational personality are important predictors of whether a childless couple has a first child or not. Interestingly, it is only the relational personality of men (i.e. not that of women) that contributes to the explanation of whether young parents with one child advance to the birth of a second child or postpone/forgo it.

Apart from the reported prominent approaches, empirical contributions to the question of the psychological determinants of childbearing behavior have been rare or marginal to the field (cf. Grant, 1993, Lechner, 2001, Barber et al., 2002), often arising from methodical weaknesses. The current state of the empirical literature thus can be

\footnotetext{
${ }^{5}$ Miller applied the personality research form, PRF, by Jackson (1984).
} 
characterized by a mix of conceptual problems as well as measurement and data problems that have led to a body of literature that is incoherent and strangely detached from recent advances in personality and life-span psychology (Asendorpf, 2002, Baltes et al., 2000, Heckhausen, 2000). The present study starts out from some of the fundamental psychological notions concerning childbearing determinants (personality, sex differences) and presents an original approach to the case drawing from a psychological longitudinal survey from eastern Germany.

\section{The conceptual and empirical background of the study}

Before we lay out our approach to first births in eastern Germany in the 1990s, we need to recall what has already been said on the particular case of eastern Germany's fertility — and ask in what way a psychological inquiry adequately contributes to it. As the primary goal of this paper is not a contribution to the broad field of "transformation research" (see, for instance, the voluminous collections by Trommsdorf, 1994, Silbereisen \& von Eye, 1999, Bynner \& Silbereisen, 2000, Sackmann et al., 2000, Bock $\&$ Fiedler, 2001), the review of the specialized literature will be brief and selective. Yet, it is important for the development of an adequate psychological approach to recall what we know about the impact of the 1990s on people's lives in eastern Germany. The focus of our reflections of the literature is on the individual and biographical prods and pressures.

\subsection{The demographic transformation of eastern Germany: Deriving an approach to childbearing in times of change}

The exceptional events connected with German unification have received their due reflection by the scientific literature. With respect to the understanding of life-courses, a number of different research discourses bear relevance, such as the sociological, ethnographic, anthropological, psychological, and demographic discourse as well as that from cultural studies. Two main perspectives can be traced in the underlying scientific 
enterprises: (i) to describe and explain the evolution, maintenance, and impact of differences between eastern and western Germans due to 40 years of political separation; and (ii) to research into the degree, direction, and consequence of the arguable attenuation of these differences. With relevance for the understanding of the childbearing behavior of eastern Germans after 1990, we would like to refer to a demographic, a sociological, and a psychological example of these research approaches.

For demographers, the striking differences between eastern and western Germans are particularly interesting With regard to childbearing behavior, eastern Germany - in contrast to the western region - has experienced a roller-coaster movement since the 1970s. Preceding 1989, GDR fertility may be termed one of early and nearly universal first (and second) childbearing. For the 1980s, Kreyenfeld (2004: 14) finds a median age for first childbirth of around 22 years in the GDR and of roughly 28 years in the $\mathrm{FRG}^{6}$. Also, childbearing took place in the GDR in a more standardized way: 50 percent of GDR women of the 1952-1957 cohorts had two children at age of 35 to 39 compared to 35 percent in the FRG where, conversely, childlessness and larger family sizes were more common. 25 percent of women from the quoted cohort in the FRG were childless (GDR: 10\%), but a family size of three and more children was more pronounced in the FRG than in the GDR (all figures from Kreyenfeld 2004). By consequence, the Total Fertility Rate $^{7}$ was temporarily up to 40 percent higher in the GDR than it was in the FRG (in 1984, cf. Council of Europe, 2001).

In 1993 - only nine years later -, eastern Germany's fertility levels reached an all-time low, the fertility rate stood 45 percent below that of western Germany-with the former GDR being among the regions with the world's lowest fertility at that time. As of

\footnotetext{
${ }^{6}$ The acronyms stand for the socialist German Democratic Republic and the democratic Federal Republic of Germany.

${ }^{7}$ We only draw on the TFR (total fertility rate) measure here, which is defined as the average life-time number of children per woman under the assumption of stable fertility behavior.
} 
today $^{8}$, the two TFRs have almost fully converged whereas other behavioral indicators of fertility behavior (age, spacing, marriage) remain surprisingly different (Konietzka \& Kreyenfeld, 2004). In eastern Germany, the transition to parenthood still occurs at younger ages, but the transition to second or higher order births is clearly postponed, if not forgone at all (Kreyenfeld, 2001). Psychologically satisfactory explanations of these differences are rare in demography which mostly recalls economic (insecurity, deprivation) or ideational (uncertainty, "belated modernization”) arguments.

Let us record that the eastern German fertility regime undoubtedly has been profoundly altered. Consequently, we hypothesize that the relatively standardized behavioral models and conceptions of eastern Germans concerning their family and fertility behavior also were challenged. In particular, and this is relevant for our study, we expect that in times when formerly standardized behavioral patterns (these hardly were conducive to individuality) give way to a future initially insecure, life-course behavior may depend more clearly on personality and other intra-personal differences.

Sociological analyses beyond a mere focus on demographic rates have attempted to pinpoint intra-German differences in the exposure to the processes of individualization and social differentiation (see Beck-Gernsheim, 1997, Dorbritz, 1998). There has been persistent discussion about the so-called "belated modernization" of eastern Germany after reunification (Geißler, 2000, Alheit et al., 2004). The term implies that the social order of the GDR was awkwardly pre-modern and has been exposed with some delay to the processes of individualization and life-style pluralism. This, in turn, would imply that fertility behavior before 1990 has to be termed "pre-modern" and the current one "belatedly modern"; an implication one may well view skeptically. Whilst the diagnosis of persevering differences in subjective orientations and mentalities is still valid (Hoffmeyer-Zlotnik, 1998, Reitzle, 1999, Alheit et al., 2004), we do not have much evidence of how far these differences help explain life-course decisions such as childbearing. Empirical studies in this field are currently conducted by the

\footnotetext{
${ }^{8}$ Current demographic comparisons of eastern and western Germany have been severely hampered by the fact that East-West vital statistics were stopped when Berlin covered up the traces of its division by forming new administrative districts in January 2001.
} 
interdisciplinary research team around Laura Bernardi and others (Bernardi et al., 2006, forthc.). There is some reason to assume that after unification, the life-course orientations of eastern Germans remain somewhat more strongly family-oriented than those of western Germans (Reitzle \& Silbereisen, 2000), in particular those of women (Merkel, 1994, Gerhard, 1994, Vondracek, 2000).

Social psychological investigations that provide a substantial contribution (Nolte, 1994) to the question of childbearing behavior in eastern Germany and its interconnection with individual traits or other life choices have been notoriously rare and little systematic over the past 15 years. One of the few focused approaches stems from the Leipzig research team around Brähler and Stöbel-Richter who, amongst other things, address intra-German differences in the dispositions of evaluation. Having conducted in 1996 and 1999 a representative cross-sectional poll of 16- to 45-year old subjects from both regions of Germany (Stöbel-Richter \& Brähler, 2000), they applied their original "Leipzig Questionnaire on Motives of a Desire for Children" (Leipziger Fragebogen zu Kinderwunschmotiven, LKM) and the "Leipzig Questionnaire for Attitudes Toward the Desire for Children" (Leipziger Fragebogen zu Einstellungen zum Kinderwunsch, LEK). The questionnaires contain respectively 24 and 16 items on various dimensions of personal motives and attitudes, linked to parenthood and family formation. On a descriptive basis the authors show that significant differences between eastern and western Germany persist; these in part even increased between 1996 and 1999. In eastern Germany, the desire for children is more strongly explained by a desire for emotional closeness and intimacy (at both time points) than in the western part. Western Germans outweigh their eastern German counterparts (i) by a stronger relevance of their fears of personal limitations and problems caused by parenthood (both time points), (ii) by their hope for a higher social status and identity by parenthood (both time points), and (iii) by the negative perception of their current economic situation (only in 1999; Stöbel-Richter et al., 2001). Another interesting side finding is given by the different levels of family planning in the two German regions. Respondents, who already have become parents, retrospectively report that one third (West) and almost 50 percent (East) of the pregnancies were unplanned. This holds for the time point of 1996 as well as of 1999. The authors point out, however, that although they consider a relatively 
large number of socio-demographic and psychological covariates, they cannot explain more than 20 percent of the motives for children.

\subsection{Research questions and hypotheses}

We see a critical communality of the aforementioned empirical approaches to childbearing in eastern Germany in the 1990s in that they do not provide a psychologically satisfying explanation that shed light on childbearing behavior as the result of people's regulation of their own development by synchronizing age-specific social or developmental tasks with their life goals. Such an approach would connect the relevant research to the recent advances of life-span psychology, which is most prominently formulated in a contemporary research program by German life-course psychologists (Baltes et al, 2000, J. Heckhausen \& H. Heckhausen, 2006, Lang \& J. Heckhausen, 2006). The approach traces individual life-course development back to life-span changes in individuals' motivation and striving to take an active part in their developmental course. Herein, developmental goals are the key category; they are subject to processes of subjective selection, optimization, and compensation (the SOCModel, see reference). Without going into greater detail, we want to record for the scope of this paper that psychological fertility research should shed light on the ways in which the life-courses of young people (in our case eastern Germans in the 1990s) was determined by their own regulatory capacities.

However, the state of the empirical literature does not allow formulating straightforward hypotheses on the transition to parenthood in transformation societies. Heckhausen \& Heckhausen (2006: 447) state that as to individual differences in the capabilities of developmental regulation, psychological research still is "in its infancy", or, on another occasion, that "almost nothing is known about the adaptive value of specific control strategies for specific developmental challenges" (J. Heckhausen, 2006: 198). The authors summarize their view on individual traits relevant for psychological research on life choices by pointing out (i) the individual ability to achieve an adaptive fit between personal objectives and available opportunities; (ii) the quality of people's goal-related behavioral control strategies; and (iii) the ability and readiness to develop and to 
commit oneself to behavioral alternatives if previous goals have to be abandoned (Heckhausen \& Heckhausen, 2006: 447).

Inspired by the life-span theory of personal control (Heckhausen \& Schulz, 1995), we hypothesize that differences in the traits of control, coping, and dispositions of actions also made a difference in partnership and fertility behavior in times of the demanding and stressful societal transformation of the GDR. We expect that people's life-course decisions were affected by the extent to which they envisaged intimate and family relations an important personal goal of development; by the way in which they dealt with problems (i.e. by coping-styles); by the way they looked at their personal future (i.e. with optimism or pessimism); and whether they pursued an active and persistent or passive and yielding behavioral strategy (i.e. differential control strategies). Moreover, in line with Miller's research findings, we argue that dispositional differences in personality had an impact at the same time.

For the aim of this study we propose four operational adaptations of the presented fundamental concepts:

(1) Coping and control. We expect that coping-styles are a concept that is of particular value when we investigate the (potential) task of family-formation in demanding circumstances. The literature provides a number of different styles and categorizations of coping. For our purpose, it is important to note that these vary also within an individual depending on the issue to be addressed. For instance, a person's coping with health problems may be different from his coping with unemployment etc. For the objective of this study, we assume - in line with the quoted evidence on stronger general family-orientation in eastern Germany (see Section 3.1) - that aspiring to both participation in the labor force and family-formation relatively early in life had (still) much the character of a "matter of course" for young adults in their 20s in eastern Germany of the 1990s. Therefore, we expect those young adults who dealt with stress in a focused and straightforward or flexible, yet purposeful way to realize their goals earlier than others. The same can be expected for those who did not give up their goals when facing stress. These strategies equal a primary control strategy in the terms of Heckhausen. By contrast, those who tended to withdraw from pursuing their goals when 
facing problems may be those who preferred not to embark on childbearing in difficult times.

(2) Optimism \& self-efficacy. There is a related, yet more general construct that has been proven to be relevant in terms of people's life course development and personal well-being, namely optimism. Often, dispositional optimism is related to a general perspective of agency. Some people believe that their future mainly is determined by their own actions and proficiency (high self-efficacy). Others believe in the effectiveness of adaptation and flexibility-or just in fate (low self-efficacy). We expect that individuals, who were more optimistic and relied more heavily on their own capacities than other people of their age, were also more willing to have children in difficult times.

(3) Life goals and developmental goals. We expect that people's life course orientations find expression in the formulation of developmental goals. One of the immediate developmental goals of people in their 20s may be the formation and cultivation of intimate relations and to form an own family. We thus hypothesize that young eastern Germans with life goals that were more strongly related to the developmental goal of the formation and cultivation of intimate relations were more prone to progress to parenthood and are so earlier than others in the 1990s.

(4) Personality. An analysis of childbearing needs to consider the dispositional differences between people that make them differentially inclined toward family life. For young eastern Germans in the 1990s, we hypothesize, - translating the cited research by Miller into the contemporary Big Five Personality Model (McCrae \& Costa, 1997 ) - that young adults with greater agreeableness and conscientiousness were more prone to start a family in eastern Germany than others. In addition, we expect that in the demanding times of social transformation, a relatively low degree of irritability (or neuroticism) was beneficial to shield intimacy intentions from social stress. This is close to the notion of a personal resilience to demands (Block, 2002: 130). Conversely, we expect that higher degrees of autonomy and extraversion made an individual pursue other goals than commitment in parenthood. 


\section{Data and method}

\section{Sample}

The data for our empirical investigation stem from a longitudinal survey conducted by the Institute for Medical Psychology of the University of Rostock (eastern Germany). The Rostock Longitudinal Study (ROLS; Meyer-Probst and Teichmann, 1984, Reis, 1997) commenced in 1970 with the purpose of investigating the life-long impact of biological, social, and psychological risk factors on human development. The initial sample consisted of 1,000 newborns and their mothers. It was collected in 1970/1971 (age $=0$ ) and then reduced to a core sample of 300 children who attended the Kinderkrippe (Kindergarten for the very young) in 1972 at age 2. Follow-up studies took place at ages $6(\mathrm{~N}=279), 10(\mathrm{~N}=268), 14(\mathrm{~N}=247), 20(\mathrm{~N}=199)$, and $25(\mathrm{~N}=212)$. Throughout the years, the main focus of interest of the ROLS has shifted to include a greater number of sociological and social psychological items. It now provides a rich selection of relevant data for research on life-course transitions and it also includes information on the fertility history of the participants from an interview-scheme performed by the author in 2002/2003 (participants' mean age: 32 years). Table 1 depicts the waves of the survey relevant to this study. We highlight in grey the two recent waves plus the phone interview upon which we base the main part of our empirical examination.

Table 1. The Rostock Longitudinal Study, 1970-2003, most relevant data sources highlighted.

\begin{tabular}{|c|c|c|c|c|c|c|}
\hline & $1^{\text {st }}$ wave & $2^{\text {nd }}$ wave & $5^{\text {th }}$ wave & $6^{\text {th }}$ wave & $7^{\text {th }}$ wave & $\begin{array}{c}\text { Phone } \\
\text { interviews }\end{array}$ \\
\hline Year & $1970 / 71$ & 1972/73 & $1984 / 85$ & $1990 / 91$ & $1995 / 96$ & $2002 / 03$ \\
\hline $\begin{array}{l}\text { Mean age } \\
\text { (subjects) }\end{array}$ & 0 & 2 & 14 & 20 & 25 & 32 \\
\hline N (subjects) & 1000 & 294 & 247 & 199 & 212 & 206 \\
\hline percent of & - & 100 & 84 & 68 & 72 & 70 \\
\hline 1972 sample & & & & & & \\
\hline
\end{tabular}


More than 30 years after the start of the study, an extraordinarily high share of 70 percent of the original sample was contacted (Table 1). In an evaluation of the studypopulation characteristics, Reis (1997: 51; own translation) finds that "the development of the study sample follows the trend of the [whole] GDR" as exemplified by increasing salaries over time (age), increasing labor-force participation, etc. Table 2 summarizes the basic socio-demographic features of the subjects at the sixth and seventh wave. We see that by age 25 the typical participant of ROLS has completed education, is employed, lives with a partner, and is childless.

Table 2. Sample characteristics and measures from the $6^{\text {th }}$ and $7^{\text {th }}$ wave of ROLS.

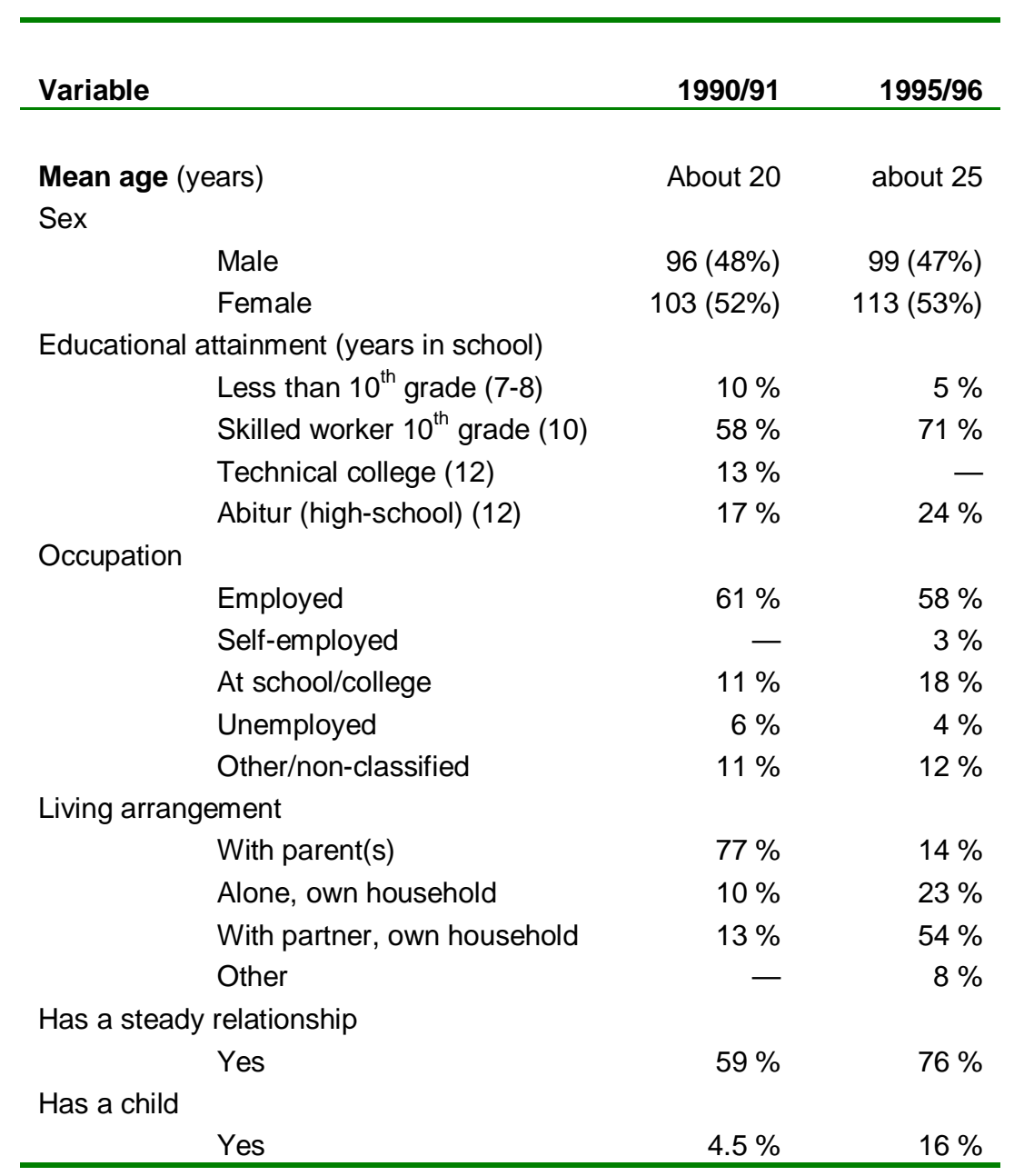

\section{Methods}

For the purpose of the statistical analysis of first birth risks, we select a set of psychological and other covariates from the sixth and seventh wave of the study in order to predict the transition to parenthood in subsequent years (prospective analysis). 
Altogether, 111 first births (39 to men and 72 to women) had occurred by the time of the phone interviews in 2002/03. As some respondents were reached in 1995/96, but not in 2002/03, these numbers refer to a total observed sample size of 241 individuals (117 men and 124 women).

We apply a hazard regression (event-history analysis) to model the risk of childbirth to childless individuals over time. A risk (hazard) is defined as the individual probability of experiencing an event at time $t$ under the condition that it has not yet been experienced. For transitions to parenthood, we first need to define a risk population of childless men and women at ages 15 and above. Individuals leave the study population either due to a first birth or owing to censoring. This means that also persons who have not been contacted since 1995/96 remain in the analysis. The method accounts for the appropriate time dependency of the process under investigation. The transition rate model is represented mathematically by

$$
\ln \mu_{i}(t)=y(t)+\sum_{k} \beta_{k} x_{i k}+\sum_{l} \lambda_{l} z_{i l}(t)
$$

where $\mu_{i}(t)$ is the hazard of occurrence of entry into parenthood at time $t$ for individual $i$, $y(t)$ captures a baseline hazard that is a function of age, $x_{k}$ is the $k$ th time constant covariate, and $z_{l}$ is the $l$ th time-varying covariate with $\beta$ and $\lambda$ as the corresponding regression parameters.

The display of the results will follow the distinct logic of event-history analyses. Vaupel \& Keilman (without year) state on this issue:

\footnotetext{
"It may be more important for an understanding of demographic behavior or other phenomena studied to know whether the inclusion of a categorical covariate in its entirety contributes significantly to an improvement of the model than to know the significance indicators of each of its levels. Such issues are often checked by means of a test, for instance a likelihood-ratio test [LLRT]. (...) Authors should be aware of the possibility of accepting statistical significance at higher p-values for small data sets than for large data sets." (paragraph 4)
}

We adopt this view and attach equal importance to the question of model-improvement (LLRT-values) as to the significance of single covariate estimates. We also report on exact p-values and use one asterisk in brackets (*) to highlight p-values up to 0.2. It is more important, however, to observe how p-values, which may initially have been low, change when we modify a model. 
Related to this is another methodical concern, namely the relatively low prevalence of events for the statistics and number of covariates we apply. This may cause a problem in that the model is over-specified, i.e. to potential difficulties with reaching the usual significance levels of effects. We respond to this by (i) interpreting trends in the results and by (ii) emphasizing that for effects that do not reach significance we cannot rule out that such may be found with higher sample sizes.

\section{Covariates}

Socio-demographic variables. The first variable of this kind is an individual's age, which we include as the basic time factor. In our study, it also picks up effects of calendar time, because the Rostock sample is based on a single cohort. In our case, age 20 corresponds to the calendar year 1990/1991, age 25 to 1995/1996, etc. Thus we are not able to disentangle age effects from period effects. The second basic demographic variable is the (time-constant) sex of any individual. Additionally, we apply two measures to capture people's socioeconomic status. First, we use the current educational attainment in years of completed education as a time-varying characteristic. Secondly, we use a measure of the occupational position of the parents of at subjects' age of 14 . The latter measure is derived from an ordinal rating that assigns a value of 1 to an unskilled worker and a value of 6 to a parent with a top managerial position or academic education. We add the values of both parents so that the final variable sums up to a maximum value of 12. (In case of missing values, we assume the average value of the population.) We attain a right-skewed distribution with a median value of 6 and a mean of 7.3 .

It is well documented in the literature that people with a high educational attainment differ in their childbearing behavior from people with a low level of education - with considerable differences between eastern and western Germany (see, for instance, Huinink 1995, Kreyenfeld 2001, Konietzka \& Kreyenfeld 2004). Following the economic framework of fertility (Becker, 1993), we expect that a higher level of an individual's education is related to a postponement of parenthood. As recent evidence suggests that the social status of the family bears relevance beyond the person's own 
educational attainment (Tölke, 2005), we include the occupational position of the parents as well.

Psychological covariates. Personality traits were measured in both relevant waves by the 120-item Trier Personality Inventory (TPI, see Becker, 1989). Table 3 describes the meaning of the five applied personality scales.

Table 3. Personality factors and their signification

\begin{tabular}{ll} 
Factor name & Signification \\
\hline $\begin{array}{l}\text { Capacity for } \\
\text { Love (LOV) }\end{array}$ & $\begin{array}{l}\text { Positive evaluation of oneself and others. Subjects with high scores are loving } \\
\text { and agreeable, mentally sound, have a high self-esteem and usually a positive } \\
\text { appraisal of others. }\end{array}$ \\
$\begin{array}{l}\text { Mental Health } \\
\text { (MHE) }\end{array}$ & $\begin{array}{l}\text { Subjects with high scores are optimistic with regard to their future, satisfied with } \\
\text { their lives and not anxious in general. They do not report depressive or } \\
\text { psychotic symptoms. }\end{array}$ \\
$\begin{array}{l}\text { Physical } \\
\text { Health (PHE) }\end{array}$ & $\begin{array}{l}\text { Subjects with high scores do not report health-related problems, have the } \\
\text { feeling that they are physically and mentally strong enough to cope with } \\
\text { demands, and have a good self-esteem. They do not report psycho-somatic }\end{array}$ \\
$\begin{array}{l}\text { Self- } \\
\text { sctualization }\end{array}$ & $\begin{array}{l}\text { Subjects with high scores are extraverted, autonomous, and risk-taking, they } \\
\text { are performance-oriented and strive for personal control. }\end{array}$ \\
$\begin{array}{l}\text { (SEA) } \\
\text { Action Control } \\
\text { (ACC) }\end{array}$ & $\begin{array}{l}\text { Subjects with high scores report an internal locus of control, they usually reflect } \\
\text { upon decisions and act in a carefully considered way. }\end{array}$ \\
\hline
\end{tabular}

We then attain a measurement of people's coping styles. These patterns were measured by a standard self-rating inventory of coping styles ("Stress-VerarbeitungsFragebogen", see Janke et al. 1997) and were gathered from respondents during interview at age 20. By means of a factor analysis (principal components, Varimax rotation), we distinguished five non-correlated coping styles based on the inventory of 114 different items. In these items respondents rated the extent to which they react to stress or demand by, for instance, getting angry, asking others for advice, or withdrawing into work. These factors are described in Table 4. Both personality traits and coping styles were standardized to c-values $(\mathrm{M}=0, \mathrm{SD}=1)$. 
Table 4. Factors of personal coping styles as derived from stress inventory.

\begin{tabular}{|c|c|}
\hline Factor name & Description \\
\hline $\begin{array}{l}\text { Withdrawal } \\
\text { (CWD) }\end{array}$ & $\begin{array}{l}\text { Coping by escape. Subjects with high scores tend to withdraw from social } \\
\text { contact and to flee from stressful demand. They also self-accuse and give up } \\
\text { more frequently. }\end{array}$ \\
\hline Control (CCO) & $\begin{array}{l}\text { Coping by control. Subjects with high scores pursue a direct, tackling and } \\
\text { straightforward strategy to obtain control over and to react self-responsibly } \\
\text { toward a stressful demand. }\end{array}$ \\
\hline $\begin{array}{l}\text { Rationalization } \\
\text { (CRA) }\end{array}$ & $\begin{array}{l}\text { Coping by rationalization. Subjects with high scores react to stress and } \\
\text { demand by persuading themselves that such a situation is unimportant, not } \\
\text { really demanding, or they do not address it at all. }\end{array}$ \\
\hline $\begin{array}{l}\text { Alternatives } \\
(\mathrm{CAL})\end{array}$ & $\begin{array}{l}\text { Coping by alternatives. Subjects with high scores prefer evasion and diversion } \\
\text { when confronted with stress and demands. They prefer turning toward easier } \\
\text { alternatives instead. }\end{array}$ \\
\hline $\begin{array}{l}\text { Drug Abuse } \\
\text { (CDA) }\end{array}$ & $\begin{array}{l}\text { Coping by substance abuse. Subjects with high scores have a stronger } \\
\text { tendency to react by the use of alcohol, barbiturates, or other types of } \\
\text { substances when confronted with stress and demands. }\end{array}$ \\
\hline
\end{tabular}

We then add two more scales that capture (i) a person's overall rating concerning her general optimism in life and (ii) a rating on how strong a person believes she can rely on her own skills and abilities. ${ }^{9}$ These covariates describe the extent to which respondents are convinced that they can realize their goals in life and how much self-efficacy they experience. Self-ratings consist of a four- and five-point Likert scale, respectively, ranging from "not optimistic/self-efficient at all" (1) to "highly optimistic/self-efficient" (4 and 5, respectively).

Finally, we draw on a rating of individual goals. Unfortunately, we do not have information on people's motivation for family-formation. Instead, the respondents were asked at ages 20 and 25 to name their "three most important desires in life". Responses varied broadly, ranging from issues of "world peace", "social justice" to "family". From these answers, we construct a variable that describes the overall desire for intimate relations by capturing the answers that contain desires such as "a family of my own", "a long-term relationship", or "family harmony". From this we create a sum score with one point per expression, which is an approximation of the developmental goal "family \&

\footnotetext{
${ }^{9}$ The respective questionnaire items read: "I will successfully go my own way" and "When planning your own future, how important do you think your own knowledge and skills are?".
} 
intimacy". In this sample, the covariate ranges from 0 to 3 . Table 5 describes the mean and range of the latter three constructs in the sample over all measurement points.

Table 5. Means and range of respondents' optimism, selfefficacy, and desire for intimacy

\begin{tabular}{lrrr}
\hline Variable & Mean & Min & Max \\
\hline Personal optimism & 3.08 & 1 & 4 \\
Self-efficacy & 4.54 & 2 & 5 \\
Desire for intimacy & 0.53 & 0 & 3 \\
\hline
\end{tabular}

\section{Results}

We start the display of findings by describing the fundamental trends of age, sex, and educational characteristics in Section 5.1. In Section 5.2, we introduce the relevant psychological covariates which were collected at ages 20 and 25. As we find substantial differences between the models for men and women, we present separate models for the sexes throughout the paper.

\subsection{Age, sex, and education}

To commence the empirical analyses, we examine how the subject's risk of first birth changes with age (Figure 1). We find that the risk increases from very low levels at ages below 20. For men, the risk is lower than for women during the whole age frame of our study, but tends to catch up with that of women at higher ages. This shows that men become parents at higher ages than do women. The age pattern also points to calendar time effects: The increase in first-birth intensities at the upper ages coincides with an increase in fertility in eastern Germany towards the end of the study period. 
Figure 1. First-birth intensities, by age, women and men.

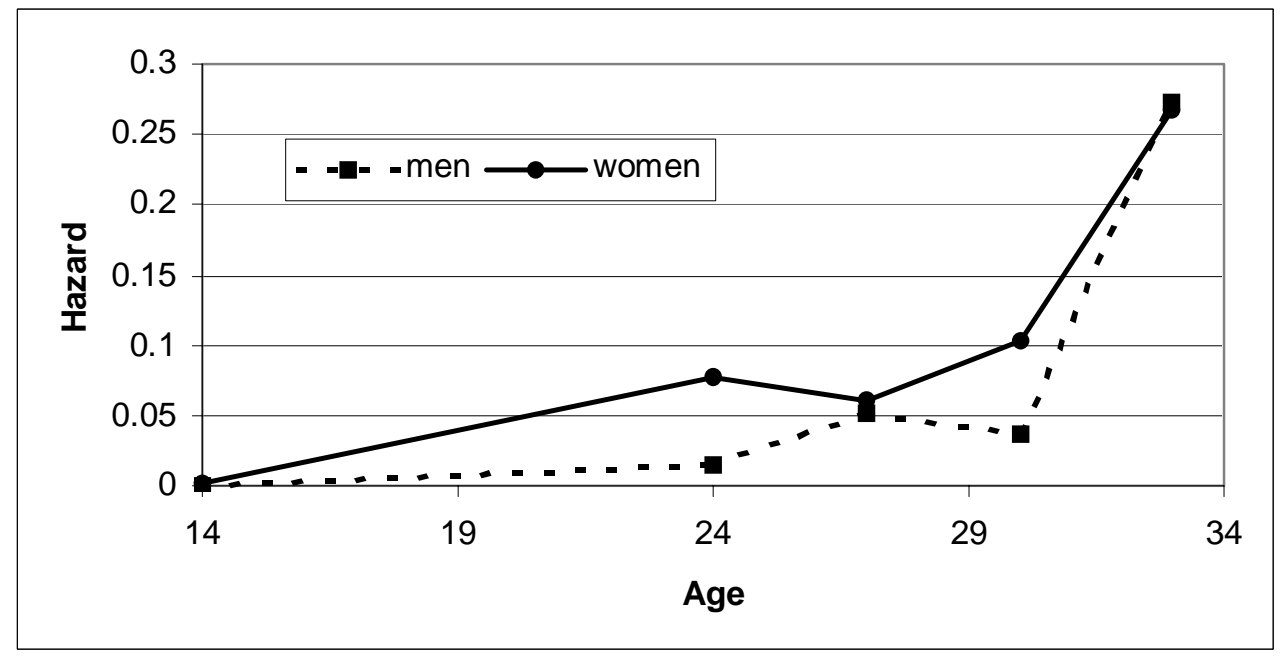

Next, we include in the model the two socio-economic variables and obtain significant positive effects of low education for female subjects and of low occupational status of their parents (Table 6). These effects are not so clear for men: it seems that the occupation of their parents has a similar impact as it has for women, while the effect of their own current educational attainment fails to reach significance at the levels we use (20 percent). 
Table 6. Relative risk of first birth, by educational variables, controlled for age. ${ }^{10}$

\begin{tabular}{|c|c|c|c|c|}
\hline & \multicolumn{2}{|r|}{ Men } & \multicolumn{2}{|c|}{ Women } \\
\hline & coeff. & $\mathrm{p}$ & coeff. & $p$ \\
\hline $\begin{array}{l}\text { Model improvement by } \\
\text { including educational variables } \\
\text { (LLRT) }\end{array}$ & & .307 & & .000 \\
\hline \multicolumn{5}{|l|}{ Individuals' current education } \\
\hline low & 2.42 & .21 & 6.11 & .01 \\
\hline average & 1 & ref. & 1 & ref. \\
\hline high & 1.75 & .24 & 0.57 & .10 \\
\hline \multicolumn{5}{|l|}{ Parents' occupational status } \\
\hline low & 1.94 & .13 & 1.80 & .04 \\
\hline average & 1 & ref. & 1 & ref. \\
\hline high & 1.22 & .69 & 1.03 & .93 \\
\hline
\end{tabular}

Note: Significance at 10-percent level indicated by bold face.

\subsection{Psychological covariates}

The analysis of the psychological determinants of first birth transitions proceeds in several steps. First, we calculate the results for each group of covariates (personality, coping-styles, others) individually. Then we exclude highly insignificant covariates from the analysis in a step-by-step procedure in order to achieve a maximum of statistical power in the model. This procedure addresses the problem of overspecification of a model which would be given if we apply, for instance, 20 covariates to predict 39 births in case of men. After the gradual fitting of the model, we then present a final model and also calculate interactions between self-efficacy and developmental goals.

Table 7 in the Appendix shows the results of the first step, namely for the groups of personality styles, coping-styles, optimism, self-centered resources, and desire for intimacy as we find them when we include each separately into the hazard regression

\footnotetext{
${ }^{10}$ In event-history models of this type, one value of a covariate is defined as the reference category (coeff $=1)$ and the other coefficients indicate the degree by which the risks of the other values differ from it.
} 
with age as a baseline. These results obviously require additional treatment as hardly any estimate attains an adequate significance level. During the gradual fitting procedure the following, highly insignificant covariates have been excluded: mental and bodily health as well as coping by control and alternatives for men; self-actualization, action control as well as coping by withdrawal and drug abuse for women. After the integration of the remaining covariates into one model, another set of insignificant covariates has been removed: coping by rationalization for men; coping by alternatives for women; the desire and fear covariate as well as general optimism for both. The results of the modified estimation for the psychological covariates are displayed in Model I in Table 8. Model II includes the educational covariates. This procedure yields interesting, yet sometimes counter-intuitive findings. 
Table 8. Two models of firth birth intensities

\begin{tabular}{|c|c|c|c|c|}
\hline & \multicolumn{2}{|c|}{$\begin{array}{r}\text { MODEL 1: } \\
\text { Psychological } \\
\text { covariates only }\end{array}$} & \multicolumn{2}{|c|}{$\begin{array}{r}\text { MODEL 2: } \\
\text { Psychological } \\
\text { covariates and } \\
\text { education }\end{array}$} \\
\hline & Men & Women & Men & Women \\
\hline \multicolumn{5}{|c|}{ Capacity for love } \\
\hline low & 1 & 1 & 1 & 1 \\
\hline & ref & ref & ref & Ref \\
\hline medium & 1.79 & 1.45 & 1.80 & 1.42 \\
\hline & $p=.29$ & $\mathrm{p}=.28$ & $\mathrm{p}=.29$ & $\mathrm{p}=.31$ \\
\hline high & 1.67 & 2.08 & 1.65 & 1.73 \\
\hline & $\mathrm{p}=.37$ & $p=.04$ & $\mathrm{p}=.42$ & $\mathrm{p}=.13$ \\
\hline \multicolumn{5}{|c|}{ Mental health } \\
\hline low & - & $\begin{array}{r}1 \\
\text { ref }\end{array}$ & - & $\begin{array}{r}1 \\
\text { Ref }\end{array}$ \\
\hline medium & - & 0.92 & - & 0.74 \\
\hline high & - & $\begin{array}{r}\mathrm{p}=.82 \\
0.70 \\
\mathrm{p}=.37\end{array}$ & - & $\begin{array}{r}p=.39 \\
0.57 \\
p=.19\end{array}$ \\
\hline \multicolumn{5}{|c|}{ Body health } \\
\hline low & - & $\begin{array}{c}1 \\
\text { ref }\end{array}$ & - & $\begin{array}{r}1 \\
\text { Ref }\end{array}$ \\
\hline medium & - & $\begin{array}{r}0.60 \\
p=.13\end{array}$ & - & $\begin{array}{r}0.63 \\
p=.17\end{array}$ \\
\hline high & - & $\begin{array}{r}1.05 \\
p=.88\end{array}$ & - & $\begin{array}{r}1.14 \\
p=.69\end{array}$ \\
\hline \multicolumn{5}{|c|}{ Self-Actualization } \\
\hline low & $\begin{array}{r}1 \\
\text { ref. }\end{array}$ & - & $\begin{array}{r}1 \\
\text { ref }\end{array}$ & - \\
\hline medium & $\begin{array}{c}0.58 \\
p=.19\end{array}$ & - & $\begin{array}{r}0.57 \\
p=.21\end{array}$ & - \\
\hline high & $\begin{array}{r}1.02 \\
p=.96\end{array}$ & - & $\begin{array}{r}1.03 \\
p=.96\end{array}$ & - \\
\hline \multicolumn{5}{|c|}{ Action Control } \\
\hline low & $\begin{array}{r}1 \\
\text { ref }\end{array}$ & - & $\begin{array}{r}1 \\
\text { ref }\end{array}$ & - \\
\hline medium & $\begin{array}{r}0.46 \\
p=.13\end{array}$ & - & $\begin{array}{r}0.47 \\
p=.17\end{array}$ & - \\
\hline high & $\begin{array}{r}0.97 \\
p=.94\end{array}$ & - & $\begin{array}{r}1.16 \\
p=.76\end{array}$ & - \\
\hline \multicolumn{5}{|l|}{ Withdrawal } \\
\hline low & $\begin{array}{r}1 \\
\text { ref. }\end{array}$ & $\begin{array}{r}1 \\
\text { ref. }\end{array}$ & $\begin{array}{c}1 \\
\text { ref }\end{array}$ & $\begin{array}{r}1 \\
\text { Ref }\end{array}$ \\
\hline medium & 0.81 & 1.62 & 0.84 & 1.60 \\
\hline high & $\begin{array}{c}p=.65 \\
0.43\end{array}$ & $\begin{array}{r}p=.18 \\
1.04\end{array}$ & $\begin{array}{c}p=.73 \\
0.49\end{array}$ & $\begin{array}{r}p=.21 \\
0.81\end{array}$ \\
\hline & $\mathrm{p}=.23$ & $\mathrm{p}=.92$ & $\mathrm{p}=.34$ & $\mathrm{p}=.61$ \\
\hline Rationalizá & & & & \\
\hline low & - & $\begin{array}{c}1 \\
\text { ref }\end{array}$ & - & $\begin{array}{r}1 \\
\text { Ref }\end{array}$ \\
\hline medium & - & $\begin{array}{r}1.23 \\
p=.59\end{array}$ & - & $\begin{array}{r}1.15 \\
p=.73\end{array}$ \\
\hline high & - & $\begin{array}{r}2.29 \\
p=.05\end{array}$ & - & $\begin{array}{l}2.05 \\
p=.09\end{array}$ \\
\hline
\end{tabular}




\begin{tabular}{|c|c|c|c|c|}
\hline & Men & Women & Men & Women \\
\hline \multicolumn{5}{|c|}{ Drug Abuse } \\
\hline low & $\begin{array}{r}1 \\
\text { ref. }\end{array}$ & - & $\begin{array}{r}1 \\
\text { ref }\end{array}$ & - \\
\hline medium & $\begin{array}{r}1.60 \\
p=.35\end{array}$ & - & $\begin{array}{r}1.79 \\
p=.31\end{array}$ & - \\
\hline high & $\begin{array}{r}2.20 \\
p=.15\end{array}$ & - & $\begin{array}{l}2.12 \\
p=.21\end{array}$ & - \\
\hline \multicolumn{5}{|c|}{ Self resources } \\
\hline low & 1 & 1 & 1 & 1 \\
\hline high & $\begin{array}{r}\text { ref. } \\
1.45 \\
p=.66\end{array}$ & $\begin{array}{r}\text { ref. } \\
0.57 \\
p=.22\end{array}$ & $\begin{array}{r}r e f \\
1.40 \\
p=.73\end{array}$ & $\begin{array}{r}\text { Ref } \\
0.78 \\
D=63\end{array}$ \\
\hline \multicolumn{5}{|c|}{$\begin{array}{l}\text { Educational } \\
\text { attainment }\end{array}$} \\
\hline low & & - & $\begin{array}{r}2.16 \\
p=.37\end{array}$ & $\begin{array}{r}5.37 \\
p=.03\end{array}$ \\
\hline medium & & - & $\begin{array}{r}1 \\
\text { ref }\end{array}$ & $\begin{array}{r}1 \\
\text { Ref }\end{array}$ \\
\hline high & & - & $\begin{array}{r}1.88 \\
p=.21\end{array}$ & $\begin{array}{r}0.56 \\
p=.12\end{array}$ \\
\hline \multicolumn{5}{|c|}{ Occupational status of parents } \\
\hline low & & - & $\begin{array}{r}1.75 \\
p=.27\end{array}$ & $\begin{array}{r}1.95 \\
p=.02\end{array}$ \\
\hline \multicolumn{2}{|l|}{ medium } & - & & $\begin{array}{r}1 \\
\text { Ref }\end{array}$ \\
\hline high & & - & $\begin{array}{r}1.28 \\
p=.67\end{array}$ & $\begin{array}{r}1.03 \\
p=.93\end{array}$ \\
\hline \multicolumn{5}{|c|}{$\begin{array}{l}\text { Improvement of fit compared to } \\
\text { the model with age only }\end{array}$} \\
\hline log-llh. & 7.4069 & 7.1424 & 2.0743 & 9.4877 \\
\hline df & 11 & 11 & 4 & 4 \\
\hline $\mathrm{p}$ & 0.19 & 0.22 & 0.39 & 0.00 \\
\hline
\end{tabular}

The strongest effect from the group of personality measures is that of a dispositional "capacity for love". For women as well as for men and in both models we find clear trends toward a positive effect for men, and a significant positive impact for women. The two dispositional health measures (mental and bodily) show an effect for women only (both models). The former exhibits even a negative impact on childbearing (if we allow a $19 \%$ error tolerance), whereas the latter has a negative U-shaped impact on childbearing risks for women. By contrast, negative U-shaped effects of dispositional self-actualization and action-control are characteristic for men.

In the group of coping-styles, we find diverging trends of "withdrawal" for the two sexes. For men, there is an indication of a trend toward a negative impact, whereas for women we observe a positive U-shaped impact on childbearing. Significant linear 
effects are obvious in case of coping by rationalization for women and by drug-abuse for men, respectively.

The findings concerning the last remaining psychological covariate (self-efficacy) is somewhat inconsistent. Whilst in Model 1 there is a trend toward a negative impact on childbearing risks of women (as opposed to a strongly insignificant positive "trend" for men), this trend disappears in Model 2. This observation is particularly unsatisfactory from a psychological perspective. A similarly unsatisfactory result is that the desire for intimate relations (which we introduced as an operationalization of a developmental goal) does not play any statistical role at all. The best result shows up for men still in Model 1 (not shown here: coeff. $=-.39, \mathrm{p}=.39$ ). We, therefore, interact both covariates (self-efficacy and goal orientation toward intimate relations) in order to get a better hold of potentially hidden connections. A full interaction procedure (that is, adding it to all covariates of Table 8) would multiply the number of covariates by Factor 3 . Therefore, we apply the procedure only to the reversed trends for the sexes in the "nutshell" covariate of self-centered resources. Table 9 presents the respective findings. We display only the part of the entire table that entails the relevant factor (all other coefficients are about stable unless we report changes).

Table 9. Results of the interaction of self-efficacy with goals for intimacy

\begin{tabular}{|c|c|c|}
\hline \multicolumn{3}{|c|}{$\begin{array}{l}\text { Interaction self-efficacy (s.e.) } \\
\text { with intimacy goals (i.g.) }\end{array}$} \\
\hline & Men & Women \\
\hline \multicolumn{3}{|l|}{ low s.e. * } \\
\hline low i.g. & 1 & 1 \\
\hline low s.e. * & ref & Ref \\
\hline high i.g. & 0.74 & 0.88 \\
\hline high s.e. * & $\mathrm{p}=.54$ & $p=.70$ \\
\hline low i.g. & 2.36 & 1.39 \\
\hline high s.e. * & $\mathrm{p}=.37$ & $p=.66$ \\
\hline high i.g. & n.a. & 0.55 \\
\hline & n.a. & $p=.33$ \\
\hline Model impr & & \\
\hline log-Ilh & 2.028 & 0.811 \\
\hline$d f$ & 2 & 2 \\
\hline $\mathrm{p}$ & 0.13 & 0.44 \\
\hline
\end{tabular}


These findings lack strict statistical significance. However, there is an indication of relevance in the model for men as the model is improved with an error probability of $13 \%$. If we interpret this trend, it seems to suggest that the higher transition risk of men with high self-efficacy is constituted by men who hold strong self-centered resources and at the same time do not explicitly express a desire for intimate relations. Conversely, the lower risks of women with high self-efficacy may be constituted by women who hold strong self-centered resources and at the same time do express family desires (bearing the same caveat of poor p-values in mind).

Finally, the results of Model 2 show that the relevance of educational variables does not disappear when we include the psychological variables in the model. For women, there is a strong negative impact of education on childbearing risks, whereas for men there is a slight negative U-shaped connection between these measures. Similar trends appear in the case of the occupational status of the parents. Note that the improvement of the model by these measures is far stronger for women than it is for men.

\section{Discussion}

\subsection{Discussion of findings}

This investigation tested the relevance of psychological concepts and scales for the explanation of the entry into parenthood of the 1970/71 cohort in eastern Germany during the 1990s. Our hypotheses were derived from psychological personality theory and life-span psychology, which emphasize the relevance of individual differences in dispositions, control-styles, optimism, and life goals for the shaping of the individual life-course. Our theoretical assumptions aimed largely at the notion of personal resilience which should facilitate young adults to pursue their family-orientations in difficult societal times, but also on the relevance of personal control-styles in order to handle life-tasks. The empirical results supported some of these ideas, yet, more characteristically, they broke new ground by unexpected findings. 
Firstly, all five personality variables and three out of five coping-styles were relevant for the statistical model of first birth intensities. Secondly, one exception apart, we did not find parallel effects for the sexes as differences between the analyses for men and women clearly prevailed. Only dispositional capacity for love was conducive to both motherhood and fatherhood-significantly for the former, as a trend for the latter. This finding is in line with prior research (Miller, 1992, see above) and confirms that there is a stable personal disposition that makes some people more prone to giving and receiving love than others. This disposition obviously was crucial for starting a family also in eastern Germany during the 1990s.

Looking at the other dispositional conditions for becoming a parent, the two other personality findings suggested that being "normally" endowed with autonomy and independence ("Self Actualization") and being an "averagely" independent decisionmaker ("Action Control") kept men away from parenthood in eastern Germany in the 1990s. We interpret this as a sign that men who were expansive and primary controllers did not aspire to parenthood commitment in these times because they, instead, actively opted for other activities and, at least, postponed childbearing. This is in line with prior research by Schneewind (2000) on the relevance of the relational personality of men (see above) and by Miller (1992) who reported a negative impact of autonomy on childbearing intentions for men. We conclude that men who were dispositionally inclined to perform exploratory rather than attachment behavior postponed or forwent childbearing in eastern Germany during the 1990s (cf. also Stöbel-Richter et al., 2001). Interestingly, the "either-or" division (either autonomous exploration or attachment) is apparently only characteristic for men's behavior. Why very high values in these traits did not show the same impact remains unclear.

The results from the analysis of coping-styles were more difficult to interpret in the case of men. The negative proportionality between an evasive, surrendering ("secondary control") coping-style and getting involved with the demands of fatherhood was not surprising at first glance. We may only ask why this finding did not show up more clearly. One possible answer points to the fact that we do not know precisely enough which evasion from what kind of demand was measured here. That is, control behavior needs to be understood in domain-specific terms (Heckhausen, 2006: 198) —and this is 
obviously more true for the "either-or species" men than for women. The second registered effect of coping-styles was more stunning, namely the positive effect of coping by drug-abuse on fatherhood risks. To our knowledge, such a connection has not been addressed in the literature so far. However, perhaps this is a counterpart of the findings on action control. Men who did not react to stress and demands in an active and independent manner ("primary control”), but instead did not spent careful consideration at all, continued to become fathers earlier than others during the 1990s. The potential link to contraceptive behavior ("happened pregnancies") or career-planning ("there's no point ...") of men may be worthwhile considering here. We come back to this interpretation at the end of this section.

The picture drawn by the results for women was an interestingly distinct one. First, women with dispositional pessimism and depression as well as those with an, at least, average degree of dispositional weakness and self-doubt had increased risks of motherhood in eastern Germany of the 1990s. This seems to reflect to a certain extent the idea of parenthood as an "exit option" for women dealing with uncertainty and strong life-course demands (Friedman et al., 1994). Women who were dispositionally more susceptible to these strains opted more readily for motherhood during the times of societal transformation, in this sense perhaps using motherhood as an alternative to the extensive processes of re-orientation and exploration. It is interesting to record that for women dispositional differences in health-related psychological traits are a crucial factor compared to the action-related traits (autonomy, action control) of men.

This interpretation was partly supported by the findings on coping-styles. Two observations pointed in a similar direction, namely the positive impact of rationalizing and self-persuading coping-style as the positive connection of an, at least, average withdrawing and eluding coping-style with the transition to motherhood. That is, women who were ready and willing to retire into oneself instead of exploring new options in an independent way experienced the transition to motherhood earlier than others.

To sum up the interpretations of our findings so far, we draw the general picture that men characterized by behavioral styles from the orbit of primary control (actionorientation) exhibit a reduced tendency toward fatherhood, those characterized by styles 
from the orbit of secondary control (state-orientation) show a stronger tendency toward fatherhood in eastern Germany during the 1990s. The latter finding is paralleled by the results for women, whereas concerning the former it is rather the lack of primary control tendencies that leads to an earlier entry into motherhood.

The results, furthermore, suggest that the transition to parenthood is, except for a weak trend, independent of the self-attributed resources in skills and knowledge (selfefficacy). An analysis of interactions revealed an interesting sex-difference. The more self-centered resources women reported and the more they missed (desired for) intimate relations, the less were they susceptible to relatively early motherhood. This is a psychological substantiation of the sociological notion of childbirth "postponement": There is a type of women who desire to have children, but put the family later because they give priority to other domains (job career, search for an adequate partner, etc.). Conversely, men with strong self-resources and a low need for intimacy become fathers earlier than others. This gives rise to the difficult questions whether or not the former observation (for women) is due to a motivational effect and the latter (for men) a selection effect of more attractive partners. These questions reach beyond the empirical scope of the paper and will be reflected upon in the following section.

\subsection{Discussion of the conceptual approach}

We have begun this theoretical and empirical investigation diagnosing a dearth of conceptual and empirical clarity in psychological research on the differential determinants of life-course transitions such as parenthood. We have proposed to address this question by focusing on personality and life-span theories. The findings suggest that this is an adequate and worthwhile, yet demanding approach.

One of the first difficulties current research has to deal with is that the life-course is a relatively young and dynamic target in contemporary psychology. Existing data and surveys rarely fit the latest theoretical and methodological advances, thus compromises are imperative. This holds, for instance, concerning statistical rigor or conceptmeasurement identity, to mention but two. A second, perhaps even more troublesome issue is the high demand on sample size and observation time that life-course research 
requires. Going beyond the sample design of classical psychological longitudinal studies, it would require a fine-meshed, long-term portray of the psychological correlates of life choices in order to understand the causal antecedents and the typical consequences of people's pathways within relevant life domains.

Both of these problems were encountered by this research and the necessary compromises had to be made. We paid unusual attention to relatively high p-values, we applied a careful step-by-step approach to statistical modeling, and we interpreted indications of trends. Still, we argue that the effort was worth while as we revealed unexpectedly large differences in the psychological pre-conditions (antecedents) of childbearing between men and women. These differences were so large that we consider the transition to parenthood to be a reflection of the psychological division of labor between the sexes. If we recall that in the German culture (like in many others) role expectations concerning fatherhood and motherhood differ, we understand why also individual pre-conditions involved in the union- and family-formation process obviously differ between the sexes in a complementary way.

This approach necessarily has to leave the pressing question for the in-depth mechanisms of childbearing decision-making unanswered. We offer some possibilities in the discussion of our findings, but concede the limitation of the applied concepts and measures. Is it mainly the partnership dynamics that translate dispositions into action? Do we need to account for the distinction between intended and unintended pregnancies in our models, and what share of behavior is explained by the "mere" contraceptive practice of people? Or is it, perhaps, an effect of mate selection and the entailed criteria of attractiveness that explains the distribution of parenthood among individuals in a given population?

In a more general view on the prospects of psychological research on life-courses, we sum up with a plea for future efforts. Firstly, we argue that the topic is highly relevant as it opens various exploratory opportunities for research and theory development. Understanding the development of the life-course on an individual level tells us much about the social world around us. And, secondly, psychological research itself can - both conceptually and methodologically - but profit from docking with the prominent life- 
course disciplines such as sociology and demography, both of which lack the crucial expertise on the decision-making and motivation-formation of people in the life-course.

\section{Acknowledgments}

The author would like to thank the Max-Planck-Institute for Demographic Research for the institutional support of this research. I particularly thank Gunnar Andersson, Olaf Reis and Frieder Lang for having contributed important advice and thought to the paper. Finally, I'd like to thank Susann Backer for editing the English.

\section{References}

Ainsaar, M. (2004). Reasons for move: a study on trends and reasons of internal migration with particular interest in Estonia 1989-2000. Turku: University of Turku.

Alheit, P., Bast-Haider, K., \& Drauschke, P. (2004). Die zögernde Ankunft im Westen. Biographien und Mentalitäten in Ostdeutschland. Frankfurt: Campus.

Baltes, P. B., Lindenberger, U., \& Staudinger, U. M. (2000). Life-span theory in developmental psychology. W. Damon, \& R. M. Lerner (eds.), The Handbook of Child Psychology. Volume 1: Theoretical Models of Human Development (5th ed., pp. 1029-1144). New York: Wiley.

Barber, J.S., Axinn, W.G., \& Thornton, A. (2002). The impact of attitudes on family formation processes. In: Ron Lesthaeghe (Ed.), Meaning and Choice: Value Orientations and Life Course Decisions. The Hague: NIDI publishing.

Beck-Gernsheim, E. (1997). Geburtenrückgang und Kinderwunsch - die Erfahrung in Ostdeutschland. Zeitschrift für Bevölkerungswissenschaft, 22(1), 59-71.

Becker, G. S. (1993). A treatise on the family. Cambridge: Harvard University Press.

Becker, P. (1989). Der Trierer Persönlichkeitsfragebogen TPF. Göttingen: Hogrefe.

Bernardi, L., von der Lippe, H., \& Klärner, A. (2006). Perceptions of job instability and the prospects of parenthood between eastern and western Germany. MPIDR Working Paper WP-2006-017, Rostock.

Bernardi, L., Keim, S. \& von der Lippe, H. (im Erscheinen). Social influences on fertility: A comparative mixed methods study in eastern and western Germany. Journal of Mixed Methods Research, $1(1)$.

Block, J. (2002). Personality as an affect-processing system. Mahwah, NJ, Lawrence Erlbaum.

Bock, K., \& Fiedler, W. (2001). Umbruch in Ostdeutschland. Politik, Utopie und Biographie im Übergang. Opladen: Westdeutscher Verlag.

BMFSFJ [Bundesministerium für Familie, Senioren, Frauen und Jugend] (Ed.) (1996). Optionen der Lebensgestaltung junger Ehen und Kinderwunsch. Verbundstudien-Endbericht. Stuttgart: Kohlhammer. 
Bynner, J., \& Silbereisen, R. K. (2000). The life course and social change. J. Bynner, \& R. K. Silbereisen (eds.), Adversity and challenge in life in the New Germany and in England (pp. 1-14). Houndsmills: Macmillan.

Council of Europe. (2001). Recent demographic developments in Europe 2000. Council of Europe Publishing.

Dorbritz, J. (1998). Der Wandel in den generativen Entscheidungen in Ostdeutschland - ein generationenspezifischer Prozeß? M. Häder, \& S. Häder (eds.), Sozialer Wandel in Ostdeutschland. Theoretische und methodische Beiträge zur Analyse der Situation seit 1990. (pp. 123-155). Opladen: Westdeutscher Verlag.

Fawcett, J. T. (1973). Psychological perspectives on population. New York: Basic Books.

Friedman, D., Hechter, M., \& Kanazawa, S. (1994). A theory of the value of children. Demography, 31(3), 175-401.

Geißler, R. (2000). Nachholende Modernisierung mit Widersprüchen. Eine Vereinigungsbilanz aus modernisierungstheoretischer Perspektive. Aus Politik und Zeitgeschichte, 40, 22-29.

Gerhard, U. (1994). Die staatlich institutionalisierte "Lösung" der Frauenfrage. Zur Geschichte der Geschlechterverhältnisse in der DDR. H. Kaelble, J. Kocka, \& H. Zwahr (eds.), Sozialgeschichte der DDR (pp. 383-403). Stuttgart: Klett-Cotta.

Grant, H.-B. (1992). Übergang zur Elternschaft und Generativität. Eine ökologisch-psychologische Studie über die Bedeutung von Einstellung und Rollenauffassungen beim Übergang zur Elternschaft und ihr Beitrag zur Generativität. Aachen: Verlag Shaker.

Heckhausen, J. (Ed.) (2000). Motivational psychology of human development. Developing motivation and motivating development. Amsterdam: Elsevier.

Heckhausen, J. (2002). Developmental regulation of life-course transitions: a control theory approach. L. Pulkkinen, \& A. Caspi (eds.), Paths to successful development: Personality in the life course (pp. 257-281). Cambridge: University Press.

Heckhausen, J. (2006). Developmental regulation in adulthood. Age-normative and sociostructural constraints as adaptive challenges. Cambrigde: University Press.

Heckhausen, J., \& Heckhausen, H. (2006). Motivation und Entwicklung. J. Heckhausen, \& H. Heckhausen (eds.), Motivation und Handeln (pp. 393-454). Berlin: Springer.

Heckhausen, J., \& Schulz, R. (1995). A lifespan theory of control. Psychological Review, 102(2), 284304.

Heckhausen, J., Wrosch, C., \& Fleeson, W. (2001). Developmental regulation before and after a developmental deadline: The sample case of "biological clock" for childbearing. Psycholoy and Aging, 16(3), 400-413.

Hoffman, L. W., \& Hoffman, M. L. (1973). The value of children to parents. J. T. Fawcett (Ed.), Psychological perspectives on population (pp. 19-76). New York: Basic Books.

Hoffmeyer-Zlotnik, J. H. P. (1998). Zur soziodemografischen Entwicklung in Ostdeutschland: Ein Vergleich 1990 mit 1996. M. Häder, \& S. Häder (eds.), Sozialer Wandel in Ostdeutschland. Theoretische und methodische Beiträge zur Analyse der Situation seit 1990. (pp. 156-191). Opladen : Westdeutscher Verlag.

Huinink, J. (1995). Warum noch Familie? Zur Attraktivität von Partnerschaft und Elternschaft in unserer Gesellschaft. Frankfurt am Main: Campus Verlag.

Jackson, D.N. (1984). Personality Research Form Manual. Fort Huron: Research Psychology Press.

Janke, W., Erdmann, G., \& Kallus, K. W. (1997). Stressverarbeitungsfragebogen SVT (2nd ed.). Göttingen: Hogrefe.

Konietzka, D., \& Kreyenfeld, M. (2004). Angleichung oder Verfestigung von Differenzen? 
Geburtenentwicklung und Familienformen in Ost- und Westdeutschland . Berliner Debatte Initial, 15(4), 26-41.

Kreyenfeld, M. (2001). Employment and fertility: East Germany in the 1990s. Dissertation. Rostock: University.

Kreyenfeld, M. (2004). Fertility decisions in the FRG and GDR: An analysis with data from the German Fertility and Family Survey. Demographic Research, Special Collection 3(11), 275-318.

Lang, F. R., \& Heckhausen, J. (2006). Allgemeine Entwicklungspsychologie der Lebensspanne: Begriffe, Theorien und Befunde. K. Pawlik (ed.), Handbuch Psychologie. Wissenschaft - Anwendungen Berufsfelder (pp. 277-292). Berlin: Springer.

Lechner, M. (2001). The empirical analysis of East German fertility after unification: An update. European Journal of Population, 17(1), 61-74.

Maier, H., \& Smith, J. (1999). Psychological predictors of mortality in old age. Journal of Gerontology: Series B, Psychological Sciences and Social Sciences, 54B(1), P44-P54.

Maier, H. McGue, M., Vaupel, J. W., \& Christensen, K. (2003). Cognitive impairment and survival in older ages. C. E. Finch, Y. Christen, \& J.-M. Robine (eds.), Research and perspectives in longevity (pp. 131-144). Berlin: Springer.

McCrae, R. R., \& Costa, P. T., Jr. (1997). Personality trait structure as a human universal. American Psychologist, 52, 509-516.

Merkel, I. (1994). Leitbilder und Lebensweisen von Frauen in der DDR. H. Kaelble, J. Kocka, \& H. Zwahr (eds.), Sozialgeschichte der DDR (pp. 359-382). Stuttgart: Klett-Cotta.

Meyer-Probst, B., \& Teichmann, H. (1984). Risiken für die Persönlichkeitsentwicklung im Kindesalter. Leipzig: Thieme.

Michaels, G. Y., \& Goldberg, W. A. (1988). The transition to parenthood. Current theory and research. Cambridge: University Press .

Miller, W. B. (1992). Personality traits and developmental experiences as antecedents of childbearing motivation. Demography, 29(2), 265-285.

Miller, W. B. (1994). Childbearing motivations, desires, and intentions: A theoretical framework. Genetic, Social, and General Psychology Monographs, 120(2), 223-258.

Miller, W. B. (1995). Childbearing motivation and its measurement. Journal of Biosocial Sciences, 27, 473-487.

Miller, W. B., \& Pasta, D. J. (1994). The psychology of child timing: A measurement instrument and a model. Journal of Applied Social Psychology, 24(3), 218-250.

Nauck, B. (2001). Der Wert von Kindern für ihre Eltern. "Value of Children" als spezielle handlungstheorie des generativen Verahltens und von Generationenbeziehungen im interkulturellen Vergleich. Kölner Zeitschrift für Soziologie und Sozialpsychologie, 53(3), 407435.

Nerdinger, F. W., Von Rosenstiel, L., Stengel, M., \& Spiess, E. (1984). Kinderwunsch und generatives Verhalten. Ausgwählte Ergebnisse einer Längsschnittstudie an jungen Ehepaaren. Zeitschrift für experimentelle und angewandte Psychologie, 31(3), 464-482.

Nickel, H., \& Quaiser-Pohl, C. (2001). Junge Eltern im kulturellen Wandel. Untersuchungen zur Familiengründung im internationalen Vergleich. Weinheim: Juventa.

Noack T. \& Ostby L. (2002), Free to choose, but unable to stick to it. Dynamics of Fertility and Partnership in Europe. New York, Geneva: United Nations, Vol. II.

Nolte, H. (1994). Sozialpsychologie als integrierende Perspektive. Versuch einer Ortsbestimmung. Zeitschrift für Sozialpsychologie, 25(4), 272-289. 
Reis, O. (1997). Risiken und Ressourcen der Persönlichkeitsentwicklung im Übergang zum Erwachsenenalter. Weinheim: PVU.

Reitzle, M. (1999). Anhaltende Kluft oder Annäherung zwischen Ost und West? Ausgewählte demoskopische Befunde. R. K. Silbereisen, \& J. Zinnecker (eds.), Entwicklung im sozialen Wandel (pp. 63-80). Weinheim: Beltz.

Reitzle, M., \& Silbereisen, R. K. (2000). Adapting to social change. Adolescent values in eastern and western Germany. J. Bynner, \& R. K. Silbereisen (eds.), Adversity and Challenge in Life in the New Germany and in England (pp. 153-169). Houndsmill: Macmillan Press.

Sackmann, R., Weymann, A., \& Wingens, M. (2000). Die Generation der Wende. Berufs- und Lebensverläufe im sozialen Wandel. Opladen: Westdeutscher Verlag.

Schneewind, K. A. (2000). Motivation for parenthood and early family development: Findings of a fiveyear longitudinal study. J. Heckhausen (Ed.), Motivational psychology of human development. Developing motivation and motivating development. (pp. 339-356). Amsterdam: Elsevier.

Silbereisen, R. K. \& von Eye, A. (eds.) (1999). Growing up in times of social change. Berlin: de Gruyter.

Stengel, M., von Rosenstiel, L., Oppitz, G., \& Spiess, E. (1983). Motivationale Determinanten des Kinderwunsches - Eine empirische Analyse an jungen Ehepaaren. Zeitschrift für experimentelle und angewandte Psychologie, 30(1), 153-173.

Stöbel-Richter, Y., Brähler, E., \& Schumacher, J. (2001). Pro und Contra eigenes Kind. Kinderwunschmotive in Ost- und Westdeutschland 1996 und 1999 im Vergleich. 17, 103-107.

Stöbel-Richter, Y., \& Brähler, E. (2000). Persönliche Kinderwunschmotive und Einstellungen zum Kinderwunsch in Ost- und Westdetuschland - Ergebnisse einer Repräsentativbefragung. In: E. Brähler, H. Felder, \& B. Strauß (eds.), Fruchtbarkeitsstörungen. Jahrbuch der Medizinihscnen Psychologie 17 (pp. 72-87). Göttingen: Hogrefe.

Trommsdorff, G. (1994). Psychologische Aspekte des sozio-politischen Wandels in Ostdeutschland. Berlin: de Gruyter.

Tölke, A. (2005). Die Bedeutung von Herkunftsfamilie, Berufsbiografie und Partnerschaften für den Übergang zur Ehe und Vaterschaft. A. Tölker, \& K. Hank (eds.), Männer, - das "vernachlässigte" Geschlecht in der Familienforschung? Sonderheft 4 der Zeitschrift für Familienforschung (pp. 98-126), VS-Verlag: Wiesbaden.

Vaupel, J.W. \& Keilman, N. (without year). Reporting Statistical Significance. The reporting of statistical significance in the online journal Demographic Research: A Letter to readers and members of our Scientific Review Board. Available at http://www.demographic-research.org/info/ reporting statistical_significance.htm. [date of access: 12.10.2006]

Von Rosenstiel, L., Nerdinger, F. W., Oppitz, G., Spieß, E., \& Stengel, M. (1986). Einführung in die Bevölkerungspsychologie. Darmstadt: Wissenschaftliche Buchgesellschaft.

Vondracek, F. W. (2000). Meeting challenges in the New Germany and in England: New directions for theory and data collection". In: R. K. Silbereisen and J. Bynner (eds.), Meeting challenges in the new Germany and in England (pp. 291-302), London: Macmillan. 


\section{Appendix}

Table 7. Relative risks of first birth for four groups of psychological covariates, included in the age baseline model.

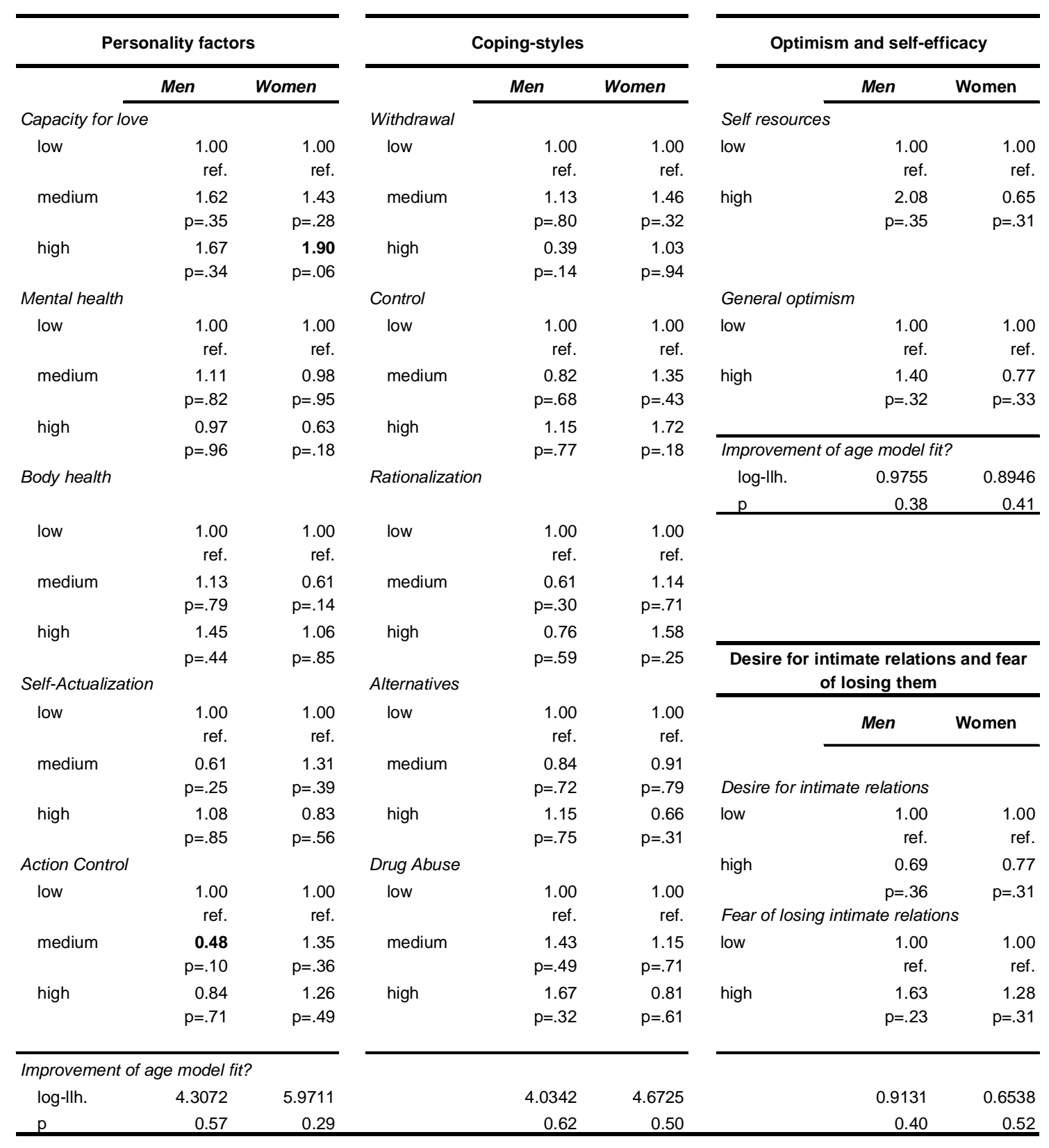

